\title{
Idiopathic Osteosclerosis of the Jaws in Turkish Subpopulation: Cone-Beam Computed Tomography Findings
}

\author{
Arzu Demir (D), Filiz Namdar Pekiner (iD) \\ Marmara University, Faculty of Dentistry, Department of Oral Diagnosis and Radiology, Istanbul, Turkey. \\ Correspondence Author: Arzu Demir \\ E-mail: dt.arzudemir@gmail.com \\ Received: $18.01 .2018 \quad$ Accepted: 13.03 .2018
}

\begin{abstract}
Objective: Idiopathic osteosclerosis (IO) was defined as an asymptomatic, incidental radiographic finding of intrabony sclerosis with unknown origin. The purpose of this retrospective study is to evaluate $\mathrm{IO}$ distribution, location, relationships and radiographic features by cone beam computed tomography (CBCT) in Turkish subpopulation.

Methods: The study group consisted of CBCT images of 279 individuals, 140 females and 139 males aged 20-69. In received images IO distribution, location in the jaws, dental and cortical relationships, shape and internal structure were evaluated. In axial and cross-sections superoinferior (SID), mesiodistal (MDD) and buccolingual (BLD) distances of $I O$ were measured. The data was compared with age groups and gender.

Results: Ninety-two IO in 75 individuals were detected with $26.9 \%$ distribution rate. There was a higher prevalence in mandible (82.6\%) than maxilla (17.4\%). The most frequently involved area was posterior mandible (43.4\%). No statistically significant difference in the distribution of IO was found between genders $(p>0.05)$. There was a higher prevalence among young group than middle-aged and above middle-aged groups $(p=0.026)$. According to relation of $\mathrm{IO}$ with dental roots separate $\mathrm{IO}(76.1 \%)$ was the most frequent relationship. Seven $\mathrm{IO}(7.6 \%)$ were detected as not related with any cortical structure. Mean SID, MDD and BLD were recorded 5.58; 4.80 and $4.18 \mathrm{~mm}$ respectively.

Conclusion: $\mathrm{IO}$ was detected at a high rate in Turkish subpopulation. CBCT was found as an efficient method to evaluate radiographic features, relationships and location of $\mathrm{IO}$ within the jaws before surgical and orthodontic operations.

Keywords: Cone beam computed tomography, Osteosclerosis, Jaw, Mandible, Maxilla.
\end{abstract}

\section{INTRODUCTION}

Idiopathic osteosclerosis (IO) is one of the terms that is used for describing intrabony sclerosis with unknown origin since 1990s (1-5). The other terms are known as 'dense bone island', 'bone scar', 'bone whorl', 'enostosis', 'eburnated bone', 'focal periapical osteopetrosis' and 'focal osteosclerosis' $(2,6-8)$. It is accepted that these lesions are almost always asymptomatic and incidental radiographic findings. None of the inflammatory, dysplastic, or neoplastic features might be seen on radiographic and histological examinations (1-9). This entity is not unique for jaw bones; it can be found mostly on pelvis, femur and the other long bones extracranially (10). Previous studies showed that 10 is commonly located at premolar-molar regions of mandible (1-10).

Even though the etiologic factors of 10 formation have not been clearly understood yet; bone reaction related with increased occlusal forces, stimulating effect of residual root fragments and sufficient blood supply, torus-like developmental anatomic variations have been discoursed as possible causes of IO formation (1, 5, 13-15, 19-22).
Radiographic image of 10 is described as localized, welldefined, non-expansile and usually homogeneous radiopaque masses potentially round, elliptic, or irregular in shape. There is no radiolucent halo around this mass; conversely characteristic radiating bony streaks blended with surrounding normal trabecular bone bring brush-like border in its appearance $(9,10)$. With this radiologic appearance; 10 can be differentiated from sclerotic lessions surrounded with radiolucent border like osteoma, osteoblastoma, periapical cemental dysplasia and from the lessions caused cortical expansion like torus and exostosis $(7,16-18)$. The distribution of IO was reported between $1.7 \%$ and $31 \%$ in many studies investigated among various populations by different radiographic equipment $(1-6,8-23)$.

Idiopathic osteosclerosis is usually required no treatment protocol because of its asymptomatic nature. However some complications caused by 10 were reported like changes in tooth position or eruption path, root resorption, obstruction or slowdown of orthodontic tooth movement $(4,24,25)$. Besides, the consequences of implant replacement in a region with IO have been unknown in default of investigation. Therefore the radiographic features of 10 such as location 
in trabecular bone, size, internal structure, borders and relationship with anatomic structures should be investigated before orthodontic treatment to regulate the biomechanical forces and surgical procedures like implant planning or maxillofacial trauma. The radiographic features explained in detailed is also necessary to differentiate 10 from other radiopaque lessions. Because many of the lessions such as osteoma, odontoma, osteoblastoma and soft tissue calsifications need treatment much as 10 need no treatment itself $(12,16-18,24,25)$.

Many studies about 10 of the jaws have been based on panoramic radiography $(2-4,8,15-22)$, which provides twodimensional (2D) aspect of image layer. Nevertheless, conebeam computed tomography (CBCT) enables clinicians to evaluate three-dimensional (3D) images of dentomaxillofacial structures with low dose of radiation compare to computed tomography (CT) (26-28). CBCT imaging techniques supports to investigate concurrently three orthogonal planes together with cross-sections. Thus the exact locations and characteristics of IO can be identified in detail $(12,14,23)$. Along with a limited number of studies were performed by CBCT to evaluate $I O$ of the jaws; fewer studies investigated distribution and radiographic features of 10 in Turkish subpopulation by CBCT $(12,14,23)$. Therefore, the purpose of this retrospective study is to evaluate distribution, location, relationships and detailed radiographic features of $\mathrm{IO}$ by $\mathrm{CBCT}$ in a Turkish subpopulation.

\section{METHODS}

The data of patients who referred to Department of Oral and Maxillofacial Radiology, Faculty of Dentistry, Marmara University with various purposes (impacted tooth, temporomandibular disorder, implant or orthodontic planning) from 2013 to 2014 were retrospectively examined and 279 patients those 20 years old and more were selected as study group. The patients with systemic or metabolic bone disease, trauma anamnesis, maxillofacial deformation and history of surgical operation of dentofacial region were excluded from the study group. The study protocol numbered as 140.014 .8979 was approved by the Local Committee of Research of Ethics of Marmara University.

Osteosclerotic lesions surrounded by radiolucent rim; clearly identifiable residual roots of deciduous or permanent teeth; radiopaque lesions associated with teeth which have deep caries, large restorations or root canal treatment; radiopaque lesions caused cortical expansion, root resorption, replacement of roots or neurovascular canals; radiopaque lesions known as tori, exostoses or soft tissue calcifications and radiopaque-radiolucent mixed lesions were also excluded from the study. Thus, the asymptomatic sclerotic areas without radiolucent border, and cortical expansion; in edentulous region, dentate region without tooth relation or related with tooth without deep caries, large restorations, root canal treatment and resorption; round, elliptical or irregular in shape and vary in size was defined as $I O$.

All projections were taken with the same radiographic equipment (Planmeca Promax SD Mid CBCT device, Helsinki, Finland, with $90 \mathrm{kVp}$ and $12 \mathrm{~mA}$ ). All tomographic images were carried out by the same technician. Romexis 2.92 software program (Planmeca Oy, Helsinki, Finland) was used for reconstruction and evaluation of all projections. The images were exported and saved as a single frame DICOM files. The assessment of images was fulfilled directly on monitor screen (N56VZ-S4283H model of Asus Computer, ASUSTeK Computer Inc. Beitou District, Taipei, Taiwan, with NVIDIA GeForce GT 650M 4GB screen cart and 15.6 inch Full HD LED 1920X1080 pixel monitor).

To ensure a professional and efficient evaluation, oral diagnosis and radiology clinician and specialist (A.D.) who had been working in the Department of Oral Diagnosis and Radiology evaluated the clinical images. During meetings for the pilot study, the clinician and radiology specialist trained to evaluate tomographic images by specialist (F.N.P.) who had been working in Oral Diagnosis and Radiology for fifteen years or more, and an agreement on the objective criteria for the qualitative evaluation of the images was forged among the evaluators.

The existence of 10 was investigated on coronal, sagittal and axial sections. Then the mandibular location of 10 was detected as incisive, canine, canine-premolar, premolar, premolar-molar, molar and angle-ramus regions; the maxillary location of 10 was detected as incisive, canine, canine-premolar, premolar, premolar-molar and molar regions on the images with 10 . The shape of 10 was defined as round, elliptical and irregular; the internal structure of $I O$ was defined as homogeneous (HO) and heterogeneous (HT) (Figure 1).
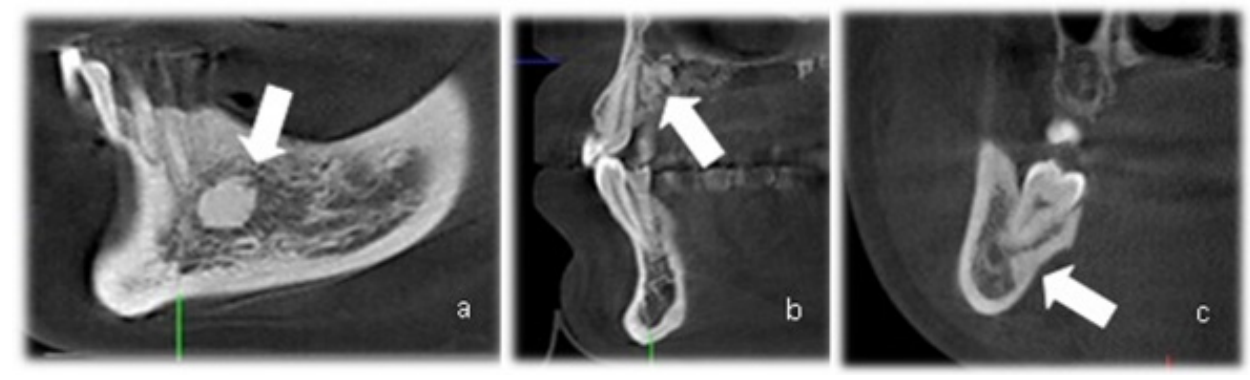

Figure 1: Arrows show homogeneous round IO in mandibular canine-premolar region (a); heterogeneous irregular IO in maxillary canine region (b) and homogeneous elliptical IO in mandibular molar region (c). 
In addition; the images with 10 were evaluated on crosssections and, the dental relationship of 10 was defined as apical, interradicular, apical-interradicular and separate; the relationship of 10 with jawbones' cortical structures was defined as buccal, lingual, buccal-lingual and separate. The IO relationship with neurovascular canal (mandibular canal, mental foramen and incisive canal) cortices and maxillary sinus or nasal floor cortices were also investigated on cross-sections (Figure 2).
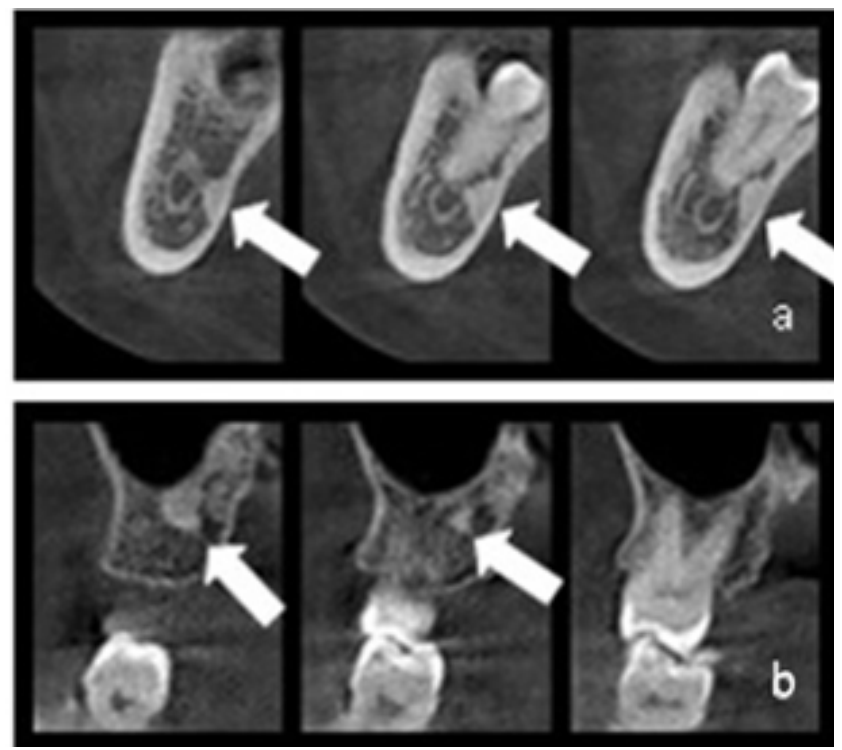

Figure 2: Arrows show lingual and mandibular canal cortex related 10 separated from dental root (a); maxillary sinus cortex related 10 separated from jawbones' cortical structures (b).

Moreover, the superoinferior (SID) and buccolingual (BLD) distances of IO were measured on cross-sections; mesiodistal (MDD) distance of IO was measured on axial sections (Figure 3). The obtained data were compared with gender and age groups.

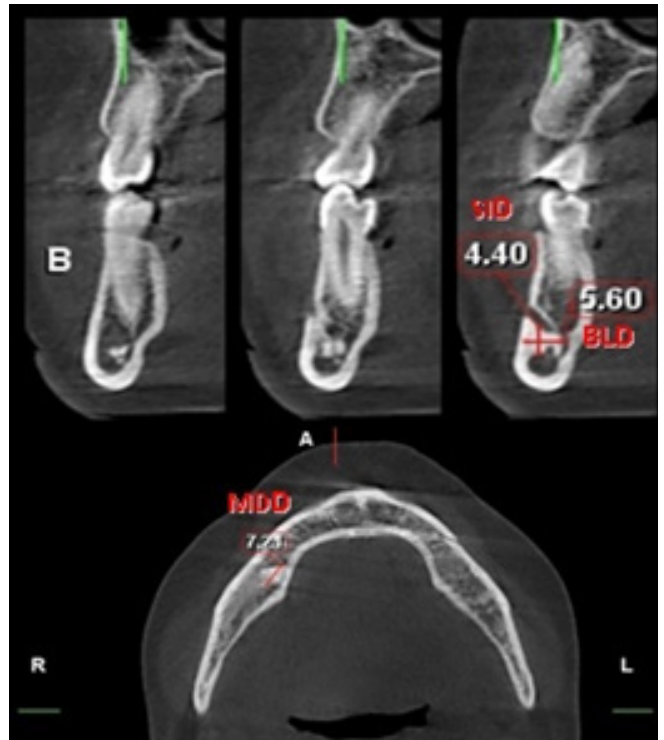

Figure 3: Measuring superoinferior (SID) and buccolingual (BLD) distances of 10 is shown on cross-section images; mesiodistal (MDD) distance of 10 on axial section.

\subsection{Statistical Analysis}

The data was analyzed with Statistical Package for Social Sciences (SPSS) for Windows 15.0 (SPSS, Inc., Chicago, Illinois). Descriptive statistical methods (mean, standard deviation and frequency) were used for evaluation of the data. One Way Anova test was used to compare quantitative data and age groups and Tukey HDS test was used to differentiate which groups caused the difference. Student t test was used to compare gender and the parameters. Chi square test, Fisher's exact test and Continuity correction were used to compare qualitative data. Values of $p<0.05$ were interpreted as significant.

\section{RESULTS}

The study group consist of 279 patients (139 males, 140 females) ranging in age from 20 to 69 years (average age $33.11 \pm 10.41$ years). One hundred twenty five of the patients were at $20-29$ age range $(44.8 \%), 87$ of the patients were at $30-39$ age range $(31.2 \%)$ and 67 of the patients were above 40 years of age $(24.0 \%)$.

In 75 patients, a total of 9210 were identified. Sixty patients had $1 \mathrm{IO}(21.5 \%), 13$ patients had 2 IOs $(4.7 \%), 2$ patients had $3 \operatorname{IOs}(0.7 \%)$.

Idiopathic osteosclerosis was detected 40 of female patients (28.6\%) and 35 of male patients (25.2\%). Females with 10 were slightly higher than males but there was no statistically significant difference between genders $(p=0.564)$.

The highest rate of 10 was found as 20-29 age range with 35 of the patients $(25.0 \%)$. Twenty two of the patients were found between $30-39$ age range $(17.1 \%)$ and 16 of the patients were found above 40 years of age (11.5\%). The occurrence of IO was significantly higher at young group than middle-aged and above 40 years of age groups $(p=0.026)$. There was no statistically significant difference between age groups either mandible $(p=0.259)$ or maxilla $(p=0.521)$. Besides there was no correlation between age groups and the occurrence of 10 in mandible or maxilla ( $p=0.233)$.

The vast majority of 10 occurred in mandible; only 1610 were detected in maxilla (17.4\%) while 7610 were detected in mandible (82.6\%). There was a statistically significant difference between jaws $(p<0.0001)$. In mandible; the occurrence of 10 in molar region (30.4\%) was significantly higher than the other regions $(p<0.0001)$; there was no statistically significant difference between maxillary regions $(p=0.623)$ (Table 1$)$

Irregular 10 (42.4\%) was found higher than round (25.0\%) and elliptical $10(32.6 \%)$ but there was no statistically significant difference between shapes $(p=0.082)$. Idiopathic osteosclerotic areas were mostly irregular (38.0\%) in mandible and elliptical (9.9\%) in maxilla. There was no statistically significant difference between shapes either mandible $(p=0.062)$ or maxilla $(p=0.144)$.

Homogeneous 10 was found 85 of the lesions (92.4\%). Round (25.0\%) and elliptical (32.6\%) IOs were all found HO. All 
Table 1: Regional distribution of 10 in jawbones.

\begin{tabular}{|c|c|c|c|c|c|c|c|c|c|c|}
\hline & Incisive & Canine & $\begin{array}{l}\text { Canine } \\
\text { Premolar }\end{array}$ & Premolar & $\begin{array}{l}\text { Premolar } \\
\text { Molar }\end{array}$ & Molar & $\begin{array}{l}\text { Angle } \\
\text { Ramus }\end{array}$ & $p$ & ${ }^{1}$ Total & $p$ \\
\hline & $n(\%)$ & $n(\%)$ & $n(\%)$ & $n(\%)$ & n (\%) & $n(\%)$ & $n(\%)$ & & $n(\%)$ & \\
\hline${ }^{1}$ Mandible & $2(2.2 \%)$ & $3(3.3 \%)$ & $6(6.5 \%)$ & $15(16.3 \%)$ & $12(13.0 \%)$ & $28(30.4 \%)$ & $10(10.9 \%)$ & $<0.0001^{*}$ & $76(82.6 \%)$ & \multirow{2}{*}{$<0.0001^{*}$} \\
\hline${ }^{1}$ Maxilla & $2(2.2 \%)$ & $1(1.1 \%)$ & $3(3.3 \%)$ & $3(3.3 \%)$ & $2(2.2 \%)$ & $5(5.4 \%)$ & - & 0.623 & $16(17.4 \%)$ & \\
\hline${ }^{2}$ Total & $4(4.3 \%)$ & $4(4.3 \%)$ & $9(9.8 \%)$ & $18(19.6 \%)$ & $14(15.2 \%)$ & $33(35.9 \%)$ & $10(10.9 \%)$ & 0.250 & 92 & \\
\hline
\end{tabular}

HT IOs were found irregular in shape (7.6\%). There was no correlation between shapes and the occurrence of $\mathrm{IO}$ as $\mathrm{HO}$ $(p=0.455)$. But it was shown that the occurrence of IO as HT was depend on the shape of $I O(p=0.006)$.

Heterogeneous 10 was found 6 in mandible (6.5\%) and 1 in maxilla (1.1\%). Homogeneous IO was found significantly higher than HT in mandible $(p<0.0001)$, maxilla $(p<0.0001)$ and total $(p<0.0001)$. There was no correlation between the occurrence of $\mathrm{IO}$ as $\mathrm{HO}$ or $\mathrm{HT}$ and the occurrence of $\mathrm{IO}$ in mandible or maxilla $(p=0.822)$.

Thirteen of the IOs were found apical (14.1\%), 6 of the IOs were found interradicular (6.5\%), 3 of the IOs were found apical-interradicular (3.3\%) relation with the dental roots and 70 of the IOs were found separate $(76.1 \%)$ from the dental roots. Separate 10 (76.1\%) was found significantly higher among dental root related IO $(p<0.0001)$.

Separate IO from jawbones' cortical structures (34.8\%) was found significantly higher than buccal cortex related 10 (20.7\%), lingual cortex related IO (31.5\%) and both buccal and lingual cortex related IO (13.0\%) $(p=0.001)$. Lingual cortex related 10 (31.5\%) was found significantly higher among the jawbones' cortical structure related IO $(p=0.026)$. Compared to total 10 related with any jawbones' cortical structures (65.2\%); separate IO from jawbones' cortical structures (34.8\%) was found significantly lower $(p=0.004)$.

Fifty six of 9210 (60.9\%) were found related with the cortical structures of neurovascular canals (53.3\%) and maxillary sinus or nasal cavity floor (7.6\%). Mandibular canal related IO (31.5\%) was found significantly higher than incisive canal related $\mathrm{IO}(5.4 \%)$ and mental foramen related $\mathrm{IO}(16.3 \%)$ $(p<0.0001)$. The IO related with any neurovascular canal cortex (53.3\%) was found significantly higher than maxillary sinus or nasal cavity floor related IO (7.6\%) ( $p<0.0001)$.

Twenty five of 32 separate 10 from jawbones' cortical structures were found related with neurovascular canals and maxillary sinus or nasal cavity floor (25.2\%). Among these separate IO from jawbones' cortical structures; neurovascular canals related IO (62.5\%) was found significantly higher than maxillary sinus or nasal cavity floor related IO (15.6\%) $(p<0.0001)$; and mandibular canal related IO (40.6\%) was found significantly higher than incisive canal related 10 (6.3\%) and mental foramen related $10(15.6 \%)(p=0.008)$.

The exact number of separate 10 from any cortical structure was found $7(7.6 \%)$ in total of 9210 . Compared to 10 related with cortical structures in anyway (92.4\%); separate IO from any cortical structure (7.6\%) was found significantly lower $(p<0.0001)$

The average dimensions of 10 were measured $4.80 \pm 2.64$ $\mathrm{mm}$ for MDD, $4.18 \pm 1.57 \mathrm{~mm}$ for BLD and $5.58 \pm 2.81 \mathrm{~mm}$ for SID. There was no statistically significant difference between gender and the average dimensions of MDD ( $p=0.610), B L D$ $(p=0.101)$ and SID $(p=0.753)$.

Except BLD ( $p=0.043)$; there was no statistically significant difference between age groups and the mean dimensions of IO ( $p=0.528$ for MDD and $p=0.173$ for SID). The mean BLD for 20-29 age group was found significantly lower than 3039 age group $(p=0.029)$ and above 40 age group $(p=0.045)$. There was no statistically significant difference in the mean BLD between age groups of 30-39 and above $40 \quad(p=0.436)$ (Table 2).

Table 2: Age distribution of the dimensions of 10.

\begin{tabular}{|c|c|c|c|c|c|c|c|c|c|c|}
\hline & \multicolumn{3}{|l|}{$20-29$} & \multicolumn{3}{|l|}{ 30-39 } & \multicolumn{3}{|c|}{ Above 40} & \multirow[b]{2}{*}{$\mathbf{p}$} \\
\hline & $\begin{array}{l}\text { Min } \\
(\mathrm{mm})\end{array}$ & $\begin{array}{l}\text { Avg } \pm S D \\
(\mathrm{~mm})\end{array}$ & $\begin{array}{l}\text { Max } \\
(\mathrm{mm})\end{array}$ & $\begin{array}{l}\text { Min } \\
(\mathrm{mm})\end{array}$ & $\begin{array}{l}\text { Avg } \pm S D \\
(\mathrm{~mm})\end{array}$ & $\begin{array}{l}\text { Max } \\
(\mathrm{mm})\end{array}$ & $\begin{array}{l}\text { Min } \\
(\mathrm{mm})\end{array}$ & $\begin{array}{l}\text { Avg } \pm S D \\
(\mathrm{~mm})\end{array}$ & $\begin{array}{l}\text { Max } \\
\text { (mm) }\end{array}$ & \\
\hline${ }^{1} \mathrm{MDD}^{\#}$ & 1.44 & $4.45 \pm 2.56$ & 13.12 & 2.00 & $5.14 \pm 2.46$ & 11.12 & 1.65 & $4.98 \pm 3.10$ & 12.46 & 0.528 \\
\hline${ }^{1} \mathbf{S I D}^{\#}$ & 2.40 & $4.95 \pm 2.12$ & 12.43 & 2.00 & $6.06 \pm 3.49$ & 18.80 & 2.80 & $6.06 \pm 2.69$ & 13.58 & 0.173 \\
\hline${ }^{1} \mathrm{BLD}^{\sharp}$ & 1.44 & $3.71 \pm 1.21$ & 6.80 & 1.70 & $4.52 \pm 1.84$ & 8.40 & 2.40 & $4.57 \pm 1.56$ & 8.25 & $0.043 *$ \\
\hline \multirow[b]{2}{*}{${ }^{2}$ BLD } & \multicolumn{3}{|c|}{$\begin{array}{l}p \\
\text { between } \\
20-29 \text { and 30-39 }\end{array}$} & \multicolumn{3}{|c|}{$\begin{array}{l}p \\
\text { between } \\
30-39 \text { and above } 40\end{array}$} & \multicolumn{3}{|c|}{$\begin{array}{l}p \\
\text { between } \\
20-29 \text { and above } 40\end{array}$} & \\
\hline & & 0.029* & & & 0.436 & & & $0.045^{*}$ & & \\
\hline \multicolumn{11}{|c|}{${ }^{1}$ Oneway ANOVA test ${ }^{2}$ Tukey HDS test $p<0,05$} \\
\hline \multicolumn{11}{|c|}{ \#MDD:MesioDistal Distanec, SIM: Superolnferior Distance, BLD: BuccoLingual Distance } \\
\hline
\end{tabular}




\section{DISCUSSION}

Trabecular structure of bone becomes narrower and cortical content of bone increases and becomes denser in line with the extent of functional requirements during remodeling process. The term of sclerosis usually describes this intrabony density difference if the process has a pathologic mechanism $(29,30)$. Clinically asymptomatic sclerotic areas detected as incidental radiographic finding without any expansion or surrounding radiolucent rim are known as idiopathic osteosclerosis unless there is inflammatory, dysplastic or neoplastic features (1-9).

Many studies investigated among various populations by different radiographic equipment reported the distribution of 10 between \% 1.7 and \% 31 mostly without gender discrimination and with mandibular posterior predominance (1-6, 8-23). The difference in ethnic groups living different geographic regions; having distinctive genetic variations, habits and addictions was implied for one of the reasons of this distribution discrepancy in addition to unstandardized IO description between investigators and difference in radiographic technique of choice $(3,6,15,16)$.

In two different study with full-mouth radiography in American population; IO distribution was reported $5.4 \%$ of 1921 patients by Geist and Katz (1) and $5.7 \%$ of 1585 patients by William and Brooks (4). Similarly in a study with CBCT, Chen et al. (12) reported IO as 5.1\% of 400 American patients.

The distribution of 10 was reported $31 \%$ of 100 patients and $1.8 \%$ of 7389 patients in Chinese population $(6,16)$. Although panoramic radiography was performed on both study, the numbers of populations were seen remarkably different. Also in Korean population; 10 was detected $2.7 \%$ of 6220 patients by full-mouth radiography and $6.7 \%$ of 2001 patients by panoramic radiography $(11,15)$. In European population; IO was detected $7.6 \%$ of 210 patients by full-mouth radiography and $2.8 \%$ of 1200 patients by panoramic radiography $(13,22)$.

In Turkish population; IO distribution was reported between $2.4 \%$ and $6.1 \%$ on the studies performed with panoramic radiography [18-21] and $4 \%$ of 500 patients on a study performed with CBCT (14).

Researchers agreed with accepting the radiopacities related with roots of teeth with deep caries, large restorations, canal treatment or crown as condensing osteitis (CO) and excluding from the studies. And as well many researchers; including of all Turkish population studies; preferred to exclude sclerotic areas detected in edentulous regions based on the probability of remaining surgical scars or residual $\mathrm{CO}$. Idiopathic osteosclerosis was reported between $2.4 \%$ and $9.5 \%$ by the studies excluded radiopacities in edentulous regions $(5,14,15,18-21)$. However, it is usually expected that $\mathrm{CO}$ is reshaped with time to normal trabecular bone area by remodeling when the cause of inflammation process is removed by dental extraction, root canal therapy, periodontal treatment or other essential treatment approaches. Although approximately $30 \%$ of $\mathrm{CO}$ is known persistent after treatment; it is almost impossible to ascertain the exact cause of these abandoned sclerotic areas a few months or years after treatment approach except without a meticulously documented history. The term of 10 is usually used to define focal sclerotic areas without knowing the cause-effect relationship for certain. On the other hand, the abandoned sclerotic areas in the edentulous alveolar bone have no correlation to any sign of infectious because of being apart from teeth $(4,6,22,29,31)$. In this context, 10 was reported between $5.1 \%$ and $11 \%$ by some other researchers preferred to include sclerotic areas in edentulous regions (3, 12, 13). In a study performed in Turkish population by CBCT; Kalyoncu et al. (14) shared the idea yet still by excluding the sclerotic areas detected in edentulous regions they reported IO $4 \%$ of 500 patients. Moreover the sclerotic areas under 3 $\mathrm{mm}$ in size were excluded from some of the studies without any justification and 10 was reported between $2.8 \%$ and $7.6 \%$ $(5,13-15,22)$.

In this study, the sclerotic areas detected in edentulous regions were included if there is no sign of cortical expansion and resorption or replacement of neighboring anatomical structures. Also the sclerotic areas under $3 \mathrm{~mm}$ in size were included since there was no explainable reason. Thus 10 distribution was found as $26.9 \%$ of 279 patients. This rate was closed to the panoramic radiography study reported IO as $31 \%$ of 100 Chinese patients by Austin and Moule [6] and higher than all of the other studies $(1-5,9,11,12-23)$.

Idiopathic osteosclerosis was mostly detected slightly higher in females without statistically significant difference $(1-6,9,11-15,17-22)$ and in mandibular posterior regions dominantly $(1-6,9,11-22)$. Similarly in this study 10 was located significantly higher in mandibular molar region $(30.4 \%)$ and there was no statistically significant difference between females (28.6\%) and males (25.2\%).

Some researchers reported the earliest age of 10 detection as around 9 years old $(9,15,16)$ and most of the studies reported 10 mostly in 20-29 and 30-39 age groups without any significant difference $(4,5,11,13,19,20,22)$. It has been thought that the detection of 10 mostly around mid-thirties was coincided with the peak of bone formation in these periods $(15,16,19,32)$. The results in this study supported this idea with the aspect of the highest disturbance of 10 in 20-29 age group; but the occurrence of IO was significantly higher at young group (25\%) than middle-aged $(17.1 \%)$ and above 40 years of age (11.5\%) groups similar with Li et al. (16).

The dimensions of 10 were measured from $0,5 \mathrm{~mm}$ to $7 \mathrm{~cm}$ by using different radiographic equipment $(2-4,6,9,12-14$, $19,21,22$ ) and in follow-up studies it was showed that 10 tend to be growing in young and stabile in adults $(4,9,13)$. Petrikowski and Peters (9) measured the mean diameter of IO $2.1 \mathrm{~mm}$ in 9-14 age group, $2.7 \mathrm{~mm}$ in 15-24 age group, 2.8 $\mathrm{mm}$ in 25-29 age group and $3.3 \mathrm{~mm}$ in mid-thirties. Kalyoncu et al. (14) supported Petrikowski and Peters (9) on the subject of increasing dimension of IO with age. 
The mean SID, MDD and BLD of 10 were measured $5.58 \mathrm{~mm}$, $4.80 \mathrm{~mm}$ and $4.18 \mathrm{~mm}$ respectively in this study. Except BLD; there was no statistically significant difference between age groups and the mean dimensions of IO. The mean BLD for 20-29 age group $(3.7 \mathrm{~mm}$ ) was found significantly lower than $30-39$ age group $(4.5 \mathrm{~mm})$ and above 40 age group ( 4.6 $\mathrm{mm})$. These results supported the developmental etiological approach of 10 formation due to its tendency of growing in young and being stabile in adults $(4,9,13,22)$.

Kalyoncu et al. (14) detected $20 \mathrm{IO}$ in CBCT and reported that round $1 \mathrm{O}(80 \%)$ in shape was significantly higher than irregular IO (80\%). Contrarily no significant difference between shapes was reported in other studies investigated 10 as round, elliptical and irregular in shape $(3,4,12,18,19)$. However, $\mathrm{HO}$ IO was reported significantly higher than $\mathrm{HT}$ on the whole $(5,9,12,14)$. Similarly in this study, there was no statistically significant difference between round (25\%), elliptical (32.6\%) and irregular (42.4\%) IO in shape and HO internal structure of IO (92.4\%) was significantly higher. Besides all round (25.0\%) and elliptical (32.6\%) IOs were found $\mathrm{HO}$ and all HT IOs were irregular (7.6\%) in shape. There was no correlation between shapes and the occurrence of $\mathrm{IO}$ as $\mathrm{HO}$. But it was shown that the occurrence of IO as HT was depend on the shape of IO.

Through limited number of studies investigated IO by CBCT; Misirlioglu et al. (19) reported $16.7 \%$ of 10 had bicortical relation, $80 \%$ IO related with mandibular canal cortex and only 1 IO located separately in trabecular bone without any cortical relation. Kalyoncu et al. (14) detected 13 IO located superior to mandibular canal and $3 \mathrm{IO}$ at inferior location but it was not stated whether these 1610 related with cortex of mandibular canal or not. Chen et al. (12) investigated 10 in Taiwanese and American cohorts and detected $21 \%$ bicortical related $10,21 \%$ buccal cortex related 10 and $29 \%$ lingual cortex related $\mathrm{IO}$ for Taiwanese cohort; $20 \%$ bicortical related IO, $40 \%$ buccal cortex related 10 and $33 \%$ lingual cortex related IO for American cohort. Supportively; Geist and Katz (1) reported a possible relation between IO formation and cortical bone formation taken shape into trabecular bone to bound anatomical structures like neurovascular bundles.

Separate 10 from jawbones' cortical structures was found $34.8 \%$, buccal cortex related 10 was $20.7 \%$, lingual cortex related 10 was $31.5 \%$ and bicortical 10 was $13.0 \%$ in this study. Compared to total IO related with any jawbones' cortical structures (65.2\%); separate IO from jawbones' cortical structures (34.8\%) was found significantly lower, similar with Misirlioglu et al. (19).

Differently from other studies; the relation of 10 with cortical structures of neurovascular canals and maxillary sinus or nasal cavity floor was also investigated in this study. Neurovascular canal cortex related 10 was found $53.3 \%$ and maxillary sinus or nasal cavity floor cortex related IO was $7.6 \%$. Among neurovascular canal cortex related IOs; mandibular canal related IO (31.5\%) was found significantly higher than incisive canal related $\mathrm{IO}(5.4 \%)$ and mental foramen related IO (16.3\%).
Idiopathic osteosclerosis detected separate from jawbones' cortical structures was reevaluated according to their relation with cortical structures of neurovascular canals and maxillary sinus or nasal cavity floor. Thus 25 of 32 separate 10 from jawbones' cortical structures (25.2\%) were found related with neurovascular canals and maxillary sinus or nasal cavity floor. Compared to IO related with cortical structures in anyway (92.4\%); separate IO from any cortical structure (7.6\%) was found significantly lower. This results supported the etiological theory suggested by Geist and Katz (1).

\section{CONCLUSION}

The distribution of 10 was found $26.9 \%$ mostly higher than the other studies because of the discrepancies about the study criteria and preferred radiographic technique. Idiopathic oscteosclerosis might be detected in any age without gender difference and dominantly in mandibular posterior regions. CBCT was found as an efficient method for detailed evaluation of 10 . The radiographic features of 10 should be explained in detailed by CBCT to make differential diagnosis if in doubt on plain films and to avoid complications before orthodontic treatment or surgical procedures like implant planning or maxillofacial trauma. Although many etiologic factors were suggested for 10 formation this mechanism has still remained unknown. Further studies with larger samples and wider age range is needed to understand better the nature and biological behavior of 10 especially in the presence of occlusal forces or implant applications.

\section{REFERENCES}

[1] Geist JR, Katz JO. The frequency and distribution of idiopathic osteosclerosis. Oral Surg Oral Med Oral Pathol. 1990; 69: 388393.

[2] MacDonald-Jankowski DS. Idiopathic osteosclerosis in the jaws of Britons and of the Hong Kong Chinese: radiology and systematic review. Dentomaxillofac Radiol. 1999; 28: 357-363.

[3] Kawai T, Hirakuma H, Murakami S, Fuchihata H. Radiographic investigation of idiopathic osteosclerosis of the jaws in Japanese dental outpatients. Oral Surg Oral Med Oral Pathol. 1992; 74: 237-242.

[4] Williams T, Brooks S. A longitudinal study of idiopathic osteosclerosis and condensing osteitis. Dentomaxillofac Radiol. 1998; 27: 275-278.

[5] Yonetsu K, Yuasa K, Kanda S. Idiopathic osteosclerosis of the jaws: panoramic radiographic and computed tomographic findings. Oral Surg Oral Med Oral Pathol Oral Radiol Endod. 1997; 83: 517-521.

[6] Austin B, Moule A. A comparative study of the prevalence of mandibular osteosclerosis in patients of Asiatic and Caucasian origin. Aust Dent J. 1984; 29: 36-43.

[7] Eversole L, Stone C, Strub D. Focal sclerosing osteomyelitis / focal periapical osteopetrosis: radiographic patterns. Oral Surg Oral Med Oral Pathol. 1984; 58: 456-460.

[8] Sun HX, Soejima H, Ishibashi A, Yamada M, Moriguchi S, Kaan L, Okano T, Yamada N. Radiographic analysis of isolated osteosclerotic lesions in the mandible: panoramic survey of 5431 dental patients. Oral Radiol. 1987; 3: 19-26. 
[9] Petrikowski CG, Peters E. Longitudinal radiographic assessment of dense bone islands of the jaws. Oral Surg Oral Med Oral Pathol Oral Radiol Endod. 1997; 83: 627-634.

[10] Greenspan A. Bone island (enostosis): current concept - a review. Skeletal Radiol. 1995; 24: 111-115.

[11] Ahn SH, Choi M, Choi KS. A radiological study on the idiopathic osteosclerosis in the jaws. Korean J Oral Maxillofac Radiol. 1994; 24: 107-113.

[12] Chen CH, Wang CK, Lin LM, Huang YD, Geist JR, Chen YK. A retrospective comparison of the frequency, distribution and radiographic features of osteosclerosis of the jaws between Taiwanese and American cohorts using cone-beam computed tomography. Oral Radiol. 2014; 30: 53-63.

[13] Halse A, Molven O. Idiopathic osteosclerosis of the jaws followed through a period of 20-27 years. Int Endod J. 2002; 35: 747-751.

[14] Kalyoncu Z, Arslan A, Kurtuluş B, Sofiyev N, Onur ÖD. Çene kemiklerinde görülen idiyopatik osteosklerozisin türk populasyonundaki sıklığının belirlenmesi (pilot çalışma). İstanb Ünv Diş Hek Fak Derg. 2012; 46: 1-10.

[15] Lee SY, Park IW, Jang I, Choi DS, Cha BK. A study on the prevalence of the idiopathic osteosclerosis in Korean malocclusion patients. Korean J Oral Maxillofac Radiol. 2010; 40: 159-163.

[16] Li N, You M, Wang H, Ren J, Zhao S, Jiang M, Xu L, Liu Y. Bone islands of the craniomaxillofacial region. J Cranio Max Dis. 2015; 2: 5-9.

[17] Marmary $Y$, Kutiner G. A radiographic survey of periapical jawbone lesions. Oral Surg Oral Med Oral Pathol Oral Radiol Endod. 1986; 61: 405-408.

[18] Miloglu O, Yalcin E, Buyukkurt MC, Acemoglu H. The frequency and characteristics of idiopathic osteosclerosis and condensing osteitis lesions in a Turkish patient population. Med Oral Patol Oral Cir Bucal. 2009; 14: 640-645.

[19] Misirlioglu M, Nalcaci R, Adisen MZ, Yilmaz S. The evaluation of idiopathic osteosclerosis on panoramic radiographs with an investigation of lesion's relationship with mandibular canal by using cross-sectional cone-beam computed tomography images. J Oral and Maxillofac Radiol. 2013; 1: 48-54.

[20] Sisman $Y$, Ertas ET, Ertas $H$, Sekerci AE. The frequency and distribution of idiopathic osteosclerosis of the jaw. Eur J Dent. 2011; 5: 409-414.
[21] Toraman Alkurt M, Sadık E, Peker I. Prevalence and distribution of idiopathic osteosclerosis on patients attending a dental school. Istanbul Universitesi Dis Hekimligi Fakultesi Dergisi. 2014; 48: 29-34.

[22] Verzak Z, Celap B, Modrić VE, Sorić P, Karlović Z. The prevalence of idiopathic osteosclerosis and condensing osteitis in Zagreb population. Acta Clin Croat. 2012; 51: 573-577.

[23] Misirlioglu M, Nalcaci R, Baran I, Adisen MZ, Yilmaz S. A possible association of idiopathic osteosclerosis with excessive occlusal forces. Quintessence Int. 2014; 45: 251-258.

[24] Nakano K, Ogawa T, Sobue S, Ooshima T. Dense bone island: clinical features and possible complications. Int J Paediatric Dent. 2002; 12: 433-437.

[25] Marques Silva L, Guimaraes AL, Dilascio ML, Castro WH, Gomez RS. A rare complication of idiopathic osteosclerosis. Med Oral Patol Oral Cir Bucal. 2007; 12: 233-234.

[26] Scarfe WC, Farman AG. What is cone-beam CT and how does it work? Dent Clin North Am. 2008; 52: 707-730.

[27] Pekiner F, Dumlu A, Borahan O. Dişhekimliğinde yeni bir çağın başlangıcı: Dental volumetrik tomografi. İstanbul Dişhekimleri Odası Dergisi. 2012; 14: 40-43.

[28] Schulze D, Heiland M, Thurmann H, Adam G. Radiation exposure during midfacial imaging using 4 and 16-slice computed tomography: cone beam computed tomography systems and conventional tomography. Dentomaxillofac Radiol. 2004; 33: 83-86.

[29] Consolaro A, Consolaro RB. Advancements in the knowledge of induced tooth movement: Idiopathic osteosclerosis, cortical bone and orthodontic movement. Dental Press J Orthod. 2012; 17: 12-16.

[30] Nanci A, Whitson SW, Bianco P. Bone. In: Ten Cate's Oral Histology: development, structure, and function. 6th Ed. C. V. Mosby, St. Louis, Missouri. 2003; p: 111-144.

[31] Ingle JI, Bakland LK, Baumgartner J. Periapical Lesions of Endodontic Origin. In: Ingle's Endodontics. 6th ed. BC Decker Inc, Hamilton, Ontario. 2008; p. 508.

[32] Rizzoli R, Ammann P, Chevalley T, Bonjour JP. Protein intake during childhood and adolescence and attainment of peak bone mass. In: Nutrition and Bone Development. Nestle Â Nutrition Workshop Series. Vol 41. Lippincott-Raven, Nestec Ltd, Philadelphia. 1999; p: 231-243.

How to cite this article: Demir A., Pekiner F. N. Idiopathic Osteosclerosis of the Jaws in Turkish Subpopulation: Cone-Beam Computed Tomography Findings. Clin Exp Health Sci 2019; 9: 117-123. DOI: 10.33808/clinexphealthsci.563958 